\title{
EL AROMA EN LA ADORACIÓN HEBREA
}

\author{
Scent in Hebrew Worship \\ O aroma na adoraçáo hebraica
}

\author{
VANSTON Irwin Archobold HookeR ${ }^{\mathrm{I}}$
}

\section{Resumen}

El presente artículo hace una exposición exegética y teológica acerca del aroma y su uso en el culto hebreo, tal como los describe el libro de Génesis. Se enfoca en la ofrenda de Noé a YHWH después del diluvio (Génesis 8,15 al 9,7), con énfasis en el verso 21 del capítulo 8, considerado por algunos antropólogos culturales como la prueba capital de que YHWH y los dioses del Antiguo

1 Doctor en Teología Bíblica del Seminario Adventista Latinoamericano de Teología, Entre Ríos, Argentina. Magíster en Divinidades de Andrews University, en Berrien Springs, Michigan. Licenciado en teología de Northern Caribbean University, Mandeville, Jamaica. Actualmente es decano de la Facultad de Teología de la Corporación Universitaria Adventista, Medellín. Ha sido pastor de la Iglesia Adventista del Séptimo Día, profesor de estudios bíblicos en la Corporación Universitaria Adventista. El presente trabajo es el resultado de una investigación en el área de la Teología Bíblica, más específicamente en el libro de Génesis. Es el resumen de los dos primeros capítulos de la tesis doctoral titulada "Hacia una Teología de la Expresión 'aroma agradable' en el Culto hebreo". Correo electrónico: teologia@unac.edu.co

Artículo recibido el 16 agosto 2016 y aprobado para su publicación el 30 noviembre 2016. 
Cercano Oriente eran de la misma naturaleza. El estudio compara y contrasta el uso del aroma en la adoración hebrea con las prácticas contemporáneas al texto bíblico. Destaca la peculiaridad del pensamiento hebreo, cuestionando de esta manera las afirmaciones de la antropología cultural que asevera que el uso del aroma en los rituales de adoración hebrea tiene el mismo origen teológico que el de otras religiones de su tiempo.

\title{
Palabras claves
}

Exégesis bíblica, Culto hebreo, Uso del aroma, Génesis 8,15-9,7.

\begin{abstract}
The article presents an exegetic and theological approach to the issue of scent and its use in the Hebrew cult, such as it is described in the Book of Genesis. It focuses on Noah's offering to YHWH after the Flood (Gen. 8:15 - 9:7), paying further attention to verse 21 of chapter eight, which is considered by some cultural anthropologists as the decisive evidence that YHWH and the gods of the Ancient Near East had the very same nature. The uses of scent in Hebrew worship are compared and contrasted to current practices of the studied biblical writing. It also emphasizes the peculiarity of Hebrew thought, thus questioning statements made by Cultural Anthropology in which it is claimed that the use of scents in the rituals of Hebrew worship has the same theological origin than that of other religions of that time.
\end{abstract}

\section{Key words}

Biblical Exegesis, Hebrew Cult, Uses of Scents, Gen. 8:15 - 9:7.

\section{Resumo}

$\mathrm{O}$ presente artigo faz uma exposição exegética e teológica sobre o aroma e seu uso no culto hebraico, tal como os descreve o livro do Gênesis. Foca-se na oferenda de Noé a YHWH depois do dilúvio (Gênesis 8, 15 a 9,7), com ênfase no verso 21 do capítulo 8, considerado por alguns antropólogos culturais com a prova capital de que YHWH e os deuses do Oriente Próximo Antigo 
eram da mesma natureza. O estudo compara e contrasta o uso do aroma na adoração hebraica com as práticas contemporâneas ao texto bíblico. Destaca a peculiaridade do pensamento hebraico, questionando assim as afirmaçóes da antropologia cultural que assevera que o uso do aroma nos rituais de adoração hebraica tem a mesma origem teológica que a de outras religióes de seu tempo.

\section{Palavras-chave}

Exegese bíblica, Culto hebraico, Uso do aroma, Gênesis 8, 15-9, 7.

\section{INTRODUCCIÓN}

El estudio de rituales y mitos en la literatura del Antiguo Cercano Oriente ha ido en aumento. ${ }^{2}$ Este incremento se observa en las publicaciones de las últimas décadas sobre rituales de adoración en Mesopotamia y algunas culturas antiguas como Egipto, Asiria, Siria, y el Levante en general ${ }^{3}$. Pero el incremento en el estudio de este tema se debe, en parte, al interés que la antropología cultural ha puesto en el tema de los rituales, con el propósito de revivir las ideologías religiosas de las culturas antiguas. Debido a estos estudios se han podido revivir, parcialmente, las prácticas religiosas y las implicaciones teológicas de estas civilizaciones antiguas para el beneficio de

2 Entre las publicaciones más recientes se encuentran las siguientes:

Wulf, David M. (1992). Current Studies on Rituals: Perspectives for the Psychology of Religion. Journal for the Scientific Study of Religion, 31 (2), 228-229. Gane, Roy. (2008). Ritual and Rhetoric in Leviticus: from sacrifice to scripture. Catholic Biblical Quarterly 70 (31), 584-585. Jenson, Philip. (2006). Sacrifice and symbol: Biblical Selamim in a ritual perspective. Journal for the Study of the Old Testament, 30 (5), 46. Mcklymond, Kathryn (2004). The nature and elements in sacrificial ritual. Method and Theory in the Study of Religion, 6 (4), 337-366.

La bibliografía publicada en las últimas décadas sobre lo rituals son bastos en el contexto religioso del Antiguo Cercano Oriente.

3 Spalinger, Anthony. (2005). Egypt, Israel, and the Ancient Mediterranean World. Journal of the American Oriental Society, 125 (2), 173-4. D. Biggs, Robert. (2007). The cult of Uruk and Babylon. Journal of Near Eastern Studies, 66 (2), 146-47. Vigano, Lorenzo. (1995). Ritual at Ebla. Jounal of Near Eastern Studies, 54, 215-222. James Davies, Douglas (2002). Anthropology and Theology. New York: Berg. pp. 81-120. 
la civilización actual, permitiendo así una mejor comprensión del origen y la cosmovisión en algunas prácticas religiosas de la actualidad. ${ }^{4}$

Por "rituales", los antropólogos culturales se refieren a la dimensión simbólica del comportamiento humano en diferentes contextos sociales y religiosos (Leach, 1968, p. 345). En el contexto religioso, la palabra "ritual" describe comportamientos humanos que involucran procedimientos repetitivos necesarios para el acercamiento del hombre a la deidad con sus ofrendas o dádivas en un acto de adoración o veneración 5 . Mircea Eliade, en su estudio sobre la historia de las religiones, muestra el nexo importante entre los rituales presentes en algunas civilizaciones modernas y su conexión con algunos rituales de la antigüedad ${ }^{6}$.

Por consiguiente, el análisis y estudio de rituales en el texto hebreo han sido influenciados grandemente por la antropología cultural, ejerciendo así cierto predominio sobre la teología judeocristiana del Antiguo Testamento. Algunas de las investigaciones contemporáneas sobre el tema han debatido de manera significativa el propósito de los sacrificios quemados y el efecto de sus aromas en el culto hebreo. Lo anterior ha causado serias controversias entre varios teólogos bíblicos que hasta la fecha no han tenido un consenso satisfactorio sobre la originalidad teológica de los sacrificios quemados en la religión hebrea ${ }^{7}$. Por un lado, muchos estudios de la antropología cultural

4 Sered, Susan S. (1993). Religious Rituals and Secular Rituals: Interpreting Models, of Child Birth in Modern, Israel Context. Sociology of Religion, 54 (1), 101-114. Rosenstock, Bruce. (2006). David's Play: Fertility Rituals and the Glory of God in 2 Samuel 6. Journal for the Studies of Old Testament, 31 (1), 63-80.

5 Leach, E. R. (1993). Ritual and Belief. Newbury Park: Associated Reading. pp. 176-183. Turner, Victor W. (1989). Ritual Symbolism, Morality, and Social Structure among the Ndembu. En Ritual Belief. New York: State University of New York. pp. 193-198. Rapport, Roy A. (1979). Ecology, Meaning and Religion. New York: North Atlantic Book. pp. $1-23$.

6 En particular, menciona el tema de los ritos y símbolos vegetales que se presentan en todas las religiones, aunque con cosmovisiones y contextos diferentes. Considera que aún en las civilizaciones modernas como en la India y algunas culturas orientales, se observan prácticas rituales que tienen su origen en Mesopotamia. Cfr.Mircea Eliade. (1974). Tratado de Historia de las religiones. Madrid: Ediciones Cristiandad. 38-48.

7 Gary Anderson se une a Milgrom en proponer, en términos concretos, que el origen de los sacrificios en Israel fue de su entorno cultural, descartando una teología propia o 
enfocan su atención en el origen de las prácticas de los sacrificios y la quema de incienso para generar aromas o fragancias en honor a las deidades en el entorno que rodeaba a Israel. En otro extremo, algunos intérpretes bíblicos consideran que los sacrificios hebreos, aunque comparten similitudes con la teología de los pueblos vecinos, en su aspecto teológico son únicos, particulares y separados totalmente de su contexto cultural ${ }^{8}$.

Pero en un punto de aparente convergencia, un número considerable de antropólogos y algunos teólogos bíblicos, consideran que la teología hebrea y la teología general de las religiones mesopotámicas y cananeas sobre el tema de los rituales para los "sacrificios" y el "aroma" que estos generan, podrían tener una fuente común". Esta fuente no es necesariamente la revelación bíblica, sino otras prácticas religiosas y culturales antiguas previas, que a través del tiempo llegaron a formar la base para una teología bíblica sobre el tema del "aroma" específicamente.

Con el propósito de contribuir a aclarar las preguntas que se han generado en torno a este asunto y evidenciar el pensamiento hebreo expresado en el libro de Génesis al respecto, el presente estudio se propone analizar a la luz del texto hebreo una ofrenda de sacrificio, en particular la presentada por Noé después del diluvio, registrada en Gn. 8,15-9,7, para al fin poder determinar si la teología hebrea, reflejada en este acto de ofrecer sacrificios quemados a $Y H W H$, tiene la misma fuente que el resto de las religiones del Antiguo Cercano Oriente.

peculiar de los hebreos. Sobre este tema confrontar: Anderson, Gary. (1987). Sacrifices and Offerings in Ancient Israel: Studies in their Social and Political Importance. Atlanta: Scholars Press.

8 Klawans, Jonathan. (1977) Purity, Sacrifice, and the Temple: Symbolism and Supersessionism in the Study of Ancient Judaism. Journal for the Study of Ancient Judaism $1,10-372$.

9 Levenson, Jon D. (1987). Justice and Righteousness in Israel and the Nations: Equality and Freedom in Ancient Israel in Light of Social Justice in Ancient Near East. Journal of Biblical Literature, 106 (3),516-518. 


\section{EL SACRIFICIO DE NOÉ}

En el libro de Génesis se registran tres ocasiones en que a $Y H W H$ se le presentaron ofrendas de sacrificios quemados de animales (Gn 4,3-4; 8,21 y 22,13). Pero sólo en Gn 8, 21 responde al aroma del holocausto, dejando grandes incógnitas en la mente del lector, pues da la impresión de que el sacrificio satisfizo un aspecto emocional de la deidad después de inhalar el aroma generado por el sacrificio de animales quemados. En el caso de la ofrenda de Noé (Gn 8,21), la respuesta al holocausto es considerada por muchos como la evidencia más clara de que $Y H W H$, como los otros dioses del Antiguo Cercano Oriente, necesitaba ser calmado o apaciguado con el aroma antes de responder con bendiciones al género humano. El verso 21 registra las siguientes palabras: "Y percibió YHWH 'aroma calmante', y dijo YHWH en su corazón, no repetiré maldición más sobre la tierra por causa del hombre, porque el propósito del corazón del hombre es malo desde su juventud. No repetiré nuevamente que sea golpeado todo ser viviente como lo he hecho".

Estas palabras constituyen el centro de la controversia con respecto al aroma en el culto hebreo ${ }^{\mathbf{1 0}}$. Aquí se afirma que $Y H W H$ percibió el aroma del sacrificio de Noé y, en respuesta, expresa arrepentimiento como consecuencia del efecto del aroma sobre sus sentidos. Seguidamente, decreta algunas bendiciones en favor de la humanidad ya que, de no ser por el aroma del sacrificio, habría obrado de otra manera.

Expresiones como "Nunca más volveré a maldecir la tierra por causa del hombre [...], nunca más volveré a destruir todo ser viviente como lo he hecho [...]", son consideradas como prueba de que el aroma tuvo un efecto emocional sobre $Y H W H$, llevándolo al arrepentimiento sobre sus actos. Estas expresiones son interpretadas como el resultado de un apaciguamiento después de ser afectado por el aroma de la carne quemada ofrecida por Noé en dicho holocausto. El hecho de haber percibido el aroma de la ofrenda, generada por el sacrificio de animales, se presta, según algunos, para confundir al intérprete moderno en cuanto a la naturaleza de $Y H W H$ como Dios. La confusión teológica, que suscita el acto de responder a la

10 Turner, Laurence A. (2000) Genesis. Sheffield, England: Sheffield Academic Press. pp. 50-51. Leupold, H.C. (1990). Exposition of Genesis. Vol. 1. Grand Rapids, Mcihigan: Baker Book House. 
ofrenda de esta manera, transmite al lector el concepto de propiciación ${ }^{11}$, según algunos, y no necesariamente expiación, como generalmente se ha entendido el propósito de estas ofrendas ${ }^{12}$.

La confusión surge porque los actos propiciatorios se asocian con la adoración de las religiones contemporáneas a Israel en dicha región, pues aquellos tenían como objetivo el acercamiento a sus dioses con la intención de calmar su ira antes de recibir respuesta a sus solicitudes. Por lo anterior, se cuestiona el acto de $Y H W H$ registrado en este texto. Aparentemente, su comportamiento es idéntico al asignado a las deidades veneradas en las religiones del Antiguo Cercano Oriente, razón por la cual surge la discusión teológica entre biblistas. ${ }^{13}$ Con referencia al pasaje bíblico en particular de Gn. 8,21, este estudio busca determinar si en la perícopa Gn. 8,15-9,7, el aroma, según el pensamiento hebreo, tenía la función de apaciguaro calmar al Dios de los hebreos; no obstante, la frase clave para entender el pensamiento hebreo se encuentra en el verso "Y respiró $Y H W H$ el aroma agradable", que ha recibido traducciones variadas, tal como lo refleja el cuadro siguiente.

\begin{tabular}{|c|c|c|}
\hline Versión & Texto original & Traducción \\
\hline La LXX & 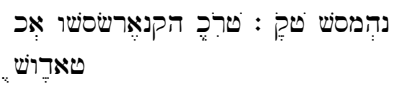 & $\begin{array}{l}\text { Y el Señor Dios olió un olor } \\
\text { de dulzura... }\end{array}$ \\
\hline La Vulgata Latina & 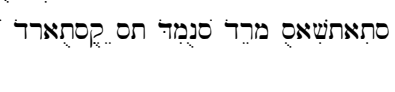 & $\begin{array}{l}\text { Y aspiró Dios el olor de } \\
\text { suavidad... }\end{array}$ \\
\hline $\begin{array}{l}\text { La Peshita versión } \\
\text { española de } 2006\end{array}$ & & $\begin{array}{l}\text { Y al percibir Dios el grato } \\
\text { aroma, olor suave... }\end{array}$ \\
\hline El Targum Neofiti & וקבל ייי ברעווה ית קרבניה & $\begin{array}{l}\text { Y percibió Dios con placer } \\
\text { este sacrificio }\end{array}$ \\
\hline $\begin{array}{l}\text { El Targum Pseudo- } \\
\text { Jonathan }\end{array}$ & וקבל ייי ברעווה ית קרבניה & $\begin{array}{l}\text { Y aceptó Dios con placer (el) } \\
\text { sacrificio... }\end{array}$ \\
\hline
\end{tabular}

11 Propiciar es ablandar o aplacar la ira de uno, haciéndolo favorable, benigno y propicio según Gispert, Carlos. (1987). Diccionario Ilustrado Océano de la Lengua Española Barcelona: Ediciones Océano, S.A. p. 798.

12 Leupold, H.C. (1990). Exposition of Genesis. Vol. 1. Grand Rapids, Mcihigan: Baker Book House.

13 Scurlock, Joan. (1998). The Techniques of Sacrifice of Animal in Israel and Ancient Mesopotamia: New Insight Through Comparison, Part 2. Andrews University Study, 44 (2), 241-264. 


\section{EL CONTEXTO TEOLÓGICO}

El contexto que rodea el evento registrado en Gn. 8,15-9,7 es de suma importancia. Aunque no existen fuentes extra-bíblicas que ayuden a esclarecer los aspectos históricos que rodean este evento del diluvio, el análisis literario de esta sección será de utilidad en la interpretación de la frase en mención. El significado de una palabra o de una frase en el texto hebreo depende, en gran parte, del contexto en el cual se menciona ${ }^{14}$. Por lo tanto, es preciso determinar en esta unidad las circunstancias en que Noé ofreció su holocausto y lo que motivó a $Y H W H$ a expresar lo que dijo sobre el aroma del sacrificio (Stuart, 2000, p. 9).

Según el testimonio bíblico, la escena final del diluvio (Gn. 8,15-9,7), tuvo lugar inmediatamente después que las aguas bajaron sobre la faz de la tierra (Gn. 8,15-16). No especifica el lugar geográfico donde el remanente del género humano comenzaría de nuevo la multiplicación de la especie ${ }^{15}$, pero sí afirma que Noé y su familia descendieron luego del arca y en forma espontánea ofrecieron holocausto a $Y H W H$ como una expresión de gratitud por haberlos salvado de la destrucción de la tierra ${ }^{16}$. La narración en sí no especifica el motivo, ni el lugar ni la fecha de lo sucedido, pero explica que los efectos del cataclismo tuvieron alcances en toda la tierra (Gn. 7,19).

El contexto hebreo declara que la causa del desastre universal fue el aumento del pecado sobre la tierra: "Vio Jehová que la maldad de los hombres era mucha en la tierra, y que todo designio de los pensamientos de su corazón sólo era de continuo al mal; y se arrepintió Jehová de haber hecho al hombre en la tierra, y le dolió en su corazón" (Gn 6,5-6). Si

14 Caird, George B. (1980). The Language and Imagery of the Bible. London: Duckworth. pp. 7-36. Este principio lo confirma igualmente Craig C. Broyles (2001), afirmando que el contexto determina el significado de un texto. Por lo tanto, es sumamente importante ubicar este pasaje en el contexto bíblico y también en el contexto social del tiempo cuando ocurrió el evento en Interpreting the Old Testament: A Guide for Exegesis.Grand Rapids: Baker Academic. p. 40.

15 El lenguaje en esta perícopa es el de los dos primeros capítulos del Génesis. Noé y su familia serían los nuevos padres del género humano. El lenguaje es el mismo de la creación, $Y H W H$ ordena al hombre que se multiplique y llene la tierra. Hay advertencias de cómo vivir en armonía con los hombres y los animales.

16 Para la mayoría de los intérpretes, el motivo de la ofrenda no era una expresión de gratitud, sino una forma de calmar la ira de $Y H W H$ sobre el género humano. 
el desastre causado por YHWH estaba relacionado con el aumento del pecado, entonces el motivo del holocausto presentado por Noé después del diluvio está relacionado con el concepto de reconciliación. Como una expresión de su reconciliación con la deidad, los hebreos dieron la ofrenda de animales quemados buscando de $Y H W H$ la purificación de sus pecados, aunque no lo expresa de esa manera el texto abiertamente. También podría estar asociado a la idea de agradecimiento por su salvación, pues tanto la idea de reconciliación como de salvación están implícitas como motivo del holocausto presentado por Noé y su familia a la deidad. Esto, desde luego, prepararía a los remanentes de la catástrofe universal a disponerse para un nuevo comienzo (Mathews, 1996, p. 29).

En este sentido, el papel del aroma que agradó tanto a la deidad podría estar asociado al concepto de expiación, ya que para la reconciliación entre $Y H W H$ y sus fieles se necesita la expiación de pecados. El texto señala igualmente que el holocausto, en donde se generó un aroma a la deidad, fue después del diluvio; por lo tanto, la ira de $Y H W H$ ya se había consumado. No podría ser que el aroma tuviese la intención de apaciguar o calmar su ira, porque independiente del sacrificio en sí, $Y H W H$ ya había consumado el acto de destruir la tierra a través del diluvio. La ofrenda se presentó al tiempo que la deidad había comenzado el proceso de reconstrucción de la tierra. En la cosmovisión hebrea, $Y H W H$ inició el proceso de recuperación del orden en el cosmos como algo totalmente ajeno a los estímulos de sacrificios o de aromas.

La actitud de Noé y su familia al proveer su ofrenda y la presentación del holocausto con el material requerido de animales limpios (Gn. 8,20), llenaron la expectativa de $Y H W H$ y respondió satisfecho a la iniciativa de los remanentes del diluvio. Su respuesta a la ofrenda fue un acto soberano de $Y H W H$, se comprometió consigo mismo $(8,21)$ : "No lo volveré a hacer", porque el problema del pecado en el pensamiento bíblico no tiene solución desde la naturaleza humana. En otras palabras, el hombre por sí mismo, no puede superar su naturaleza pecaminosa. La ira de $Y H W H$ en el contexto de esta perícopa es sobre el pecado y los que se aferran a él, por lo cual salvó a los que obedientemente entraron al arca. Aunque prometió no volver a castigar al hombre de la misma manera, en ningún momento expresó complacencia con la vida licenciosa de sus fieles. 


\section{CONTEXTO HISTÓRICO}

Debido a la semejanza entre el relato bíblico sobre el evento del diluvio y relatos similares sobre las mismas prácticas religiosas en los textos antiguos extra-bíblicos de la vida religiosa en el Antiguo Cercano Oriente, el papel del aroma en el culto hebreo ha sido considerado como un reflejo o una evolución de la teología de estas culturas antiguas (Muller, 2008, p. 292). La interpretación de estas prácticas hebreas se hace bajo la suposición de una progresión teológica y religiosa de civilizaciones más antiguas que llegaron luego a formar parte de los rituales de la religión hebrea. Por esta razón, la función del aroma en el culto hebreo ha sido objeto de mucha controversia al momento de su interpretación ${ }^{17}$. No obstante, un análisis cuidadoso de dichas prácticas registradas en el Pentateuco revela unas diferencias de fondo al comparar las acciones de $Y H W H$ con los otros dioses del Antiguo Cercano Oriente (Oswalt, 2009, p. 209). Existe diferencia tanto en su cosmovisión como en su teología.

La redacción histórica de uno de los eventos universales de mayor impacto sobre la humanidad, el diluvio universal, tenía varias versiones en la mitología egipcia ${ }^{18}$ y otras culturas antiguas de la región ${ }^{19}$. Relata una de las mitologías egipcias cómo el dios $R a$, para contrarrestar un atentado de la humanidad, decide destruir el mundo; pero después de una destrucción parcial causada por el ojo de $R a$, el dios del Sol, $R a$ detuvo la matanza (Hallo, p. 20). Para la mitología egipcia, el diluvio fue local y causado por el enojo de uno de los dioses. La ira de los dioses paganos siempre tenía preocupados

17 Las discusiones sobre el papel del aroma en los sacrificios, tanto en el culto hebreo como en las religiones del Antiguo Cercano Oriente, se puede leer en fuentes como las siguientes: Nakhai, Beth Albert. (2001). Archaeology and the Religions of Canaan and Israel. En Arqueology and the Religions of Canaan and Israel, Vol. 7 (pp. 19-36). Victor Mattews (Ed.). Boston MA: American School of Oriental Research. Romerowski, Sylvain. (2007). Old Testament Sacrifices and Reconciliation. European Journal of Theology, 16 (1) (2007), 1-11.

18 La versión egipcia Memphis Creation Account (COS 1.15; RANE \# 9; ANET 4-6; AEL 1:51-57; OTP 3-5). William W. Hallo y K. Lawson Younger, eds. (2003). The Context of Scripture, vol 1. Leiden, Netherlands: Brill.

19 Hess, Richard S. (1978). One Hundred Years of Comparison Studies on Genesis 1-11: Ancient Near Easter, Literary and Near Eastern Approach to Genesis 1-11. Richard S. Hess y David Toshio Tsumura (Eds.). Glasgow Bible College. pp.4-9. 
a los fieles, su afán de calmarlos constituía una parte fundamental del culto. Es así como en la épica de Atra-hasis del Antiguo Cercano Oriente se relata una experiencia similar a la del diluvio. Presenta una historia secuencial de la creación de la humanidad y su casi exterminio en el diluvio. En este contexto, la preocupación del adorador era satisfacer los caprichos de la deidad igualmente (p. 7). El concepto de procurar satisfacer los caprichos de los dioses no era parte de la teología hebrea. En el Pentateuco, es $Y H W H$ quien busca al hombre, quien toma la iniciativa de servir a la humanidad y este concepto es evidente en el pacto entre $Y H W H$ y los hebreos registrado en Gn. 12,1-3. No esperaba que sus adoradores le ofrecieran sacrificios para actuar en su favor.

La diferencia radical entre los mitos mesopotámicos y el relato bíblico sobre el diluvio está enmarcada en su cosmovisión. Mientras que en los relatos mesopotámicos es la sobrepoblación o el ruido de la humanidad lo que interrumpe el sueño de los dioses y provoca sus iras, y luego es la sabiduría y la valentía del héroe lo que lo salva (Oswalt, 2009, p. 209), en el texto hebreo es la iniquidad de la humanidad lo que provoca la ira de $Y H W H$ y es luego la justicia de Noé y no su sabiduría ni su valentía lo que motiva a Dios para salvarlo. La narrativa bíblica está calculada para adjudicar a $Y H W H$ toda la sabiduría y promover obediencia y confianza en él. En los relatos mesopotámicos, los dioses se reúnen alrededor de los sacrificios porque tienen hambre; en el relato bíblico, el sacrificio de Noé ablanda el corazón de $Y H W H$ en relación con el pecado (Waltke, 2007, p. 291).

\section{COSMOVISIÓN HEBREA DE LOS SACRIFICIOS}

La teología expresada en el texto hebreo contrasta significativamente con las religiones del Antiguo Cercano Oriente. En las narraciones mitológicas, los dioses necesitaban el cuidado de los humanos para desarrollar sus actividades cósmicas (Wenham, 2008, pp. 1-30). La comida de los dioses era fundamental para mantener su presencia entre los fieles y mantener el orden cósmico; por lo tanto, la función del aroma en los rituales de sacrificios o generados por la quema de vegetales tenían la intención de atraer a los dioses y de complacerlos para mantener el orden cósmico. 
Esta teología contrasta ampliamente con la teología hebrea. En el caso de Noé, el aroma de los sacrificios no tenía el propósito de atraer a $Y H W H$, porque el texto afirma que antes del holocausto la deidad ya estaba actuando en la reconstrucción y ordenación del mundo afectado por la catástrofe. El texto hebreo afirma que $Y H W H$ se acordó de Noé durante los días del diluvio y mandó que los vientos se detuvieran y comenzaron a bajar las aguas $(\mathrm{Gn} .8,1)$. En el contexto del diluvio bíblico, la Deidad no pidió nada en calidad de compensación para salvar a los redimidos, ni para iniciar en su favor actos salvíficos. No hay indicio en la narración bíblica que muestre que el Dios de los hebreos esperaba ser alimentado con sacrificios ni estar apaciguado por el aroma de los mismos para actuar en su favor. La reorganización de la tierra devastada, según la narración hebrea, comenzó como un acto soberano de $Y H W H$.

La escena que es objeto de estudio (Gn. 8,15-9:7), donde $Y H W H$ actúa en favor de la reconstrucción de la tierra y habla a sí mismo después de respirar el aroma, transmite un mensaje importante al lector hebreo, que debe ser entendido desde el punto de vista del autor bíblico. Aquí las acciones de $Y H W H$ y sus palabras son expresadas en términos antropomórficos. Esta escena ilustra la idea revelada que desea transmitir, y es que $Y H W H$ está cerca y es sensible a la iniciativa de sus criaturas y responde con bendiciones cuando el hombre lo busca en adoración.

En el relato bíblico, los términos antropomórficos describen a $Y H W H$ en términos humanos. Así, por ejemplo, el rostro de $Y H W W$ denota su presencia (Sal. 4,6), los ojos de $Y H W H$ indican su conciencia acerca de algo (Sal. 11,4), su oído significa que está atento a la peticiones de sus fieles (Sal. 17,1), el olfato de $Y H W H$ revela su presencia o su aceptación (Lv. 26,31; 1 Sam. 26,19; Amós 5,21-22). En estos pasajes donde el Dios de los hebreos rechaza la ofrenda quemada de sus fieles, se utiliza el mismo verbo que en Gn. 8,21. Cuando $Y H W H$ acepta una ofrenda, la inhala, la respira; de no ser así, rechaza la ofrenda, no la respiraría. Este concepto es claro en las citas antes mencionadas donde $Y H W H$ les dice a sus fieles claramente que por su desobediencia a sus preceptos (Lv. 26,27) no olería sus suaves aromas (Lv. 26,31). El acto de oler o percibir el aroma en la teología hebrea significa aceptación de la misma por parte de la deidad.

De esta manera, en el contexto literario, la frase controversial: "[...] y percibió $Y H W H$ el aroma agradable [...]”, se debe entender como un acto 
de aceptación por parte de $Y H W H$ de la ofrenda de Noé. Lo acepta porque fue ofrecida según su voluntad, entre otras cosas fueron animales limpios (Gn. 9,20); los sacrificados eran una exigencia de la deidad hebrea. Esta aceptación no está conectada a una situación de enojo o de ira de $Y H W H$, pues su ira ya había sido consumada con anterioridad.

Es probable que este comportamiento de la deidad sea similar al de los dioses paganos del Antiguo Cercano Oriente en el contexto de la adoración. El uso de aromas y la quema de sacrificios eran prácticas religiosas comunes en esta época y en esta región. No obstante, hay una gran diferencia en lo teológico entre lo que registra el texto hebreo y las prácticas de las otras religiones, de allí la posibilidad de que la expresión sea también utilizada en el lenguaje del culto pagano circundante de aquel entonces.

\section{ANÁLISIS SEMÁNTICO}

Además del contexto histórico y bíblico en el cual se interpreta esta perícopa con respecto al aroma en los sacrificios, es indispensable mirar la frase en su contexto semántico. El uso del término רוהה es variado en el Antiguo Testamento. Se repite sólo 11 veces; en dos ocasiones como verbo (Gn. 8,21; 27,27), en las otras instancias como sustantivo (Jos. 10,12- 13, Job 31,26; Sal. 121,6; 148,6). Este vocablo se traduce al castellano como "respirar" u "oler", cuando se usa como verbo. Como sustantivo adjetivado lleva la idea de "ser amplio", "espacioso"(Schokel, 1999). Aunque la raíz de este vocablo es הַרו que significa "espacioso" o "refrescarse" como se usa en 1 S. 16,23 y Job 32,20, otros consideran que el vocablo debe entenderse mejor como un sustantivo antiguo relacionado con una vocal 'yin de la raíz רוה "respirar", hyr "olor", y que en el idioma ugarítico, su raíz es hr (Harris, 1980, p. 836). Su uso en el Antiguo Testamento es como sustantivo la mayoría de las veces. Sólo en el libro de Génesis, en el contexto de la ofrenda a Noé, se usa como verbo que tiene como sujeto a $Y H W H$.

Una idea básica de esta palabra es la descripción del aire en movimiento. Tiene la connotación de aliento, simbolizando en algunos contextos el poder o su ausencia. Tal es el caso de esta referencia (1 R. 10,5), donde la reina de Saba, según el texto, no tuvo más ruah, queriendo decir: "Se quedó sin aliento". Puede trasmitir el sentido de asombro, resultando la persona sin 
poder. También puede significar coraje, como en el caso de Jos. 2,11; 5,1 donde los enemigos de Israel se quedaron sin coraje o sin fuerzas. Otro sentido que transmite es "valor" (Lm. 4,20), donde el rey davídico era el aliento del olfato, por los valores espirituales que encarnón ${ }^{20}$.

En Gn. 8,21 $Y H W H$ respiró el aroma, pero después, en el resto del Pentateuco, la frase se usa como un adjetivo sustantivado en donde la emisión del aroma de los sacrificios tiene como objeto a la deidad, mientras que en Génesis $Y H W H$ era el sujeto que percibía el aroma. Esta práctica de ofrecer sacrificios a la divinidad no era particular de los israelitas; también lo hacían los pueblos paganos en las naciones vecinas de Israel, pero el significado que los hebreos le imprimen era diferente en sus prácticas religiosas ${ }^{21}$.

Comenta un autor, refiriéndose al uso de esta palabra en los rituales de adoración donde el olfato juega un papel muy importante, que se debe tener en cuenta que el sentido del olfato no tiene la precisión que tiene el sentido de la vista o el sentido de la percepción auditiva. El efecto físico del olfato permite que un olor fuerte tenga un poder emocional especial ${ }^{22}$. Por tanto, el olor, o el aroma, tiene un papel importante en el ritual, ya que pretende afectar las emociones de la deidad. ¿¿Será que los hebreos utilizaron el término con el objetivo de afectar las emociones de $Y H W H$ y hacer que realizara acciones, motivado por la afección de sus sentidos? El Antiguo Testamento presenta a un Dios que actúa en favor de su pueblo, sin esperar ofrenda alguna como una motivación para iniciar dichas acciones.

Los objetos que generan aromas son los que se reducen a sus partículas más finas. Por lo tanto, esta palabra puede usarse como una expresión idiomática para describir la impresión más fina sobre el olfato de cualquier

20 Pero su uso en el resto de Pentateuco es más variado aún. Fuera del contexto de los rituales, esta misma palabra como sustantivo significa "luna," quizás por ser un objeto que pertenece al espacio (Jos 10,12-13; Job 31,26; Sal 121,6; Is 13,10; Ez 32,7). Ésta es una palabra polisémica, pues muestra diferentes connotaciones en sus significados, generalmente alrededor de una idea principal. Por lo anterior, la frase que es objeto de estudio debe entenderse en su rango general para distinguir su posible significado en determinados contextos.

21 Para los hebreos no se trataba de satisfacer un capricho de $Y H W H$ o de satisfacer su hambre para que luego éste les concediese sus retribuciones. Este era el sentido en que los gentiles ofrecían sus sacrificios, pero no en el contexto de la vida religiosa de Israel.

22 New International Dictionary Old Testamente Exegesis, ver "smell". 
cosa. Una referencia a esta realidad se encuentra en Job 14,19: "El agua desgasta las piedras, sus torrentes se llevan el polvo de la tierra; así destruyes tú la esperanza del hombre". En resumen, este vocablo describe el acto de percibir el aire con sus elementos, es el aroma de sustancias que trae el viento. En el resto del Pentateuco, en las narraciones de los rituales de los sacrificios quemados, esta palabra hace referencia a la fragancia que emana de la carne de animales asados sobre el fuego o vegetales cuyas sustancias llegan al olfato reducidas por el fuego.

Este sustantivo J!nin_deriva de la raíz hwn y sólo se usa en el contexto de las ofrendas a $Y H W H$. hwn es "movimiento hacia el descanso" y por lo tanto, la palabra hynh es realmente llevar a un descanso. También se usa para conceder un regalo y dar "satisfacción" - con esta idea se usa en Proverbios 29 y Éxodo 33 -. De las dos palabras que componen la expresión, esta es la más controvertida en el contexto de los rituales de adoración. La traducción literal de esta frase, según los diccionarios, es "calmante" o "suavizante"23 y estas dos posibles traducciones llevan implícito el concepto teológico de "propiciación" en el sentido pagano. Pero la raíz hwn con este significado nunca se usa para transmitir la idea de causar placer o satisfacción a los sentidos sino una satisfacción espiritual. Cuando la frase se traduce "como aroma calmante" o "aroma placentero", se entiende como uno que afecta los sentidos, en este caso, los sentidos de $Y H W H$.

Entendiendo el planteamiento anterior, no cabe duda alguna de que esta palabra hwhyn en la forma piel, expresa la satisfacción dada a los deseos o esfuerzos de la deidad y no a sus sentidos, como el apetito, por ejemplo (Cassuto, p. 119). Por lo tanto, hwhyn hyr "aroma agradable", en el contexto de los rituales de adoración, debe entenderse como el aroma que llena de satisfacción a $Y H W H$, un deseo recibido y no que el aroma en sí causa placer a sus sentidos (Levy, p. 163). Por ende, la idea detrás de las palabras hwhyn hyr es una expresión de complacencia o satisfacción a la voluntad de Dios. Cuando la ofrenda se presenta bajo las indicaciones de $Y H W H$, lo llena de satisfacción. El hombre que presenta ofrenda a Dios debe seguir siempre

23 Francis Brown, "hhyn" The New Brown-Driver-Briggs-Gesenius Hebrew and English Lexicon, (Peabody, Massachusetts: Hendrickson Publishers, 1979), 629. Por otro lado, Schokel, traduce el término como "aroma que aplaca" y agrega que es propia del culto en Gn 8,21; Ex 29,18 y otras citas bíblicas donde la frase se utiliza (Diccionario Bíblico Hebreo Español, ver "hhyn"). 
su voluntad, esta acción lo satisface. Es una indicación de que el adorador esta presto a cumplir su voluntad en todo aspecto de su vida, pero más aún en la presentación de sus dádivas a él (Levy, p. 164).

En el verso 16, el verbo acy está en el imperativo, al dar la orden de salir del arca: "sal del arca..."; en 9,1, el verbo פרה y también el verbo alem están en el modo imperativo. El primero se usa para ordenar a los nuevos habitantes de la tierra que se multipliquen sobre la tierra y el segundo para mandarlos a que sean fructíferos en la multiplicación de la especie humana. En Génesis 9,7 se repiten de nuevo los verbos para ordenar la repoblación de la tierra en el imperativo שרבץ יפרה. El verbo en el imperativo se utiliza para dar mandatos (Arnold, p. 63). En el contexto del Génesis, el imperativo o el $y u s i v o^{24}$ se utilizaron igualmente en el contexto de la creación del universo.

Este aspecto gramatical destaca el concepto de soberanía que ejerce $Y H W H$ tanto en la creación como en la reconstrucción y repoblación de la tierra después del diluvio. Al mismo tiempo descarta cualquier posibilidad de que la deidad necesitase ser primero calmada o apaciguada para actuar en este proceso, ya que sus órdenes de repoblar y fructificar habían comenzado mucho antes de expresar satisfacción por el holocausto de Noé25. Además, el uso repetitivo de los verbos en imperativo al interior de la perícopa , proyecta el concepto de autoridad de parte de $Y H W H$ en el proceso de reconstrucción de la tierra después del diluvio ${ }^{26}$. Esta redacción debe contrastarse con las narraciones del mismo evento en la literatura extra-bíblica para resaltar el propósito del autor bíblico al narrar esta historia a los hebreos recién salidos de Egipto (Currid, 1997, p. 272).

$24 \mathrm{El}$ yusivo, un modo verbal en hebreo, se utiliza también para dar mandatos en la gramática hebrea (Arnold, p. 62).

25 Debido a la presuposición de que la narración bíblica sobre el diluvio fue copiada de las narraciones mitológicas del Antiguo Cercano Oriente, se presume que la teología del aroma en estos rituales es apaciguar a la deidad o satisfacer su hambre con estos sacrificios (Bechmann, "Durf im Alten Testament", 49-98; y Nakai, "Archaeology and the Religions of Canaan and Israel”, 20-23).

26 De esta manera el autor descarta la validez de cualquier otra versión del diluvio que pudiese estar al alcance de sus lectores. Mientras que en las narraciones de la mitología mesopotámica o egipcia el sacrificio o el holocausto presentado es para atraer a los dioses o para espantar a los demonios, en la narración bíblica $Y H W H$ comenzó su trabajo de reconstrucción mucho antes de expresar satisfacción con el aroma (Walton, Ancient Near Eastern Thought and the Old Testament, 131). 
El uso frecuente del verbo en el modo imperativo en esta escena es muy similar a la narración de los dos primeros capítulos de Génesis. $Y H W H$ ordena y las cosas se hacen ${ }^{27}$. Creación por decreto y recreación igualmente por decreto, resaltan el concepto de soberbia y autoridad. La traducción literal sería "y olió $Y H W H$ el aroma aceptable". Otro aspecto gramatical importante es el uso de una figura literaria para transmitir el concepto de satisfacción de $Y H W H$ con relación a la ofrenda. Es una expresión antropomórfica pero bien dirigida para explicar varios aspectos de la naturaleza de $Y H W H$. En primer lugar, su agrado con la ofrenda de Noé, pues las ofrendas no siempre eran del agrado del Señor, y en algunos casos eran rechazadas. No siempre los olores de los holocaustos lo agradaban. El rechazo estaba relacionado con un procedimiento incorrecto, por un lado, o un espíritu incorrecto de quien lo ofrece, por el otro.

Es de observar también en este contexto que, en ningún momento, este sacrificio se ofrece a la deidad en un contexto de enojo o de ira, lo que descarta por consiguiente cualquier idea que asocie esta acción por parte de $Y H W H$ como propiciatorio en su naturaleza. Todo lo contrario, Dios por su soberana decisión había dado inicio a sus actos de repoblación antes del holocausto de Noé. Boer critica esta idea y en algún sentido rechaza el concepto de que el sacrificio de Noé no tenía propósitos propiciatorios. Estas son sus palabras:

La historia del sacrificio de Noé después del diluvio parece haber causado una decisión inmediata: $Y H W H$ olió un aroma suavizante - aunque debo añadir aquí que muchos traductores, haciendo un esfuerzo por repeler la idea de que Noé pudo suavizar a Dios, han aceptado alegremente la lectura de las antiguas versiones: Fragancia de olor dulce - y YHWH toma una decisión favorable para la humanidad. No seguirá maldiciendo la tierra ${ }^{28}$.

En realidad, como se demuestra desde el análisis semántico, no es una aceptación alegre de las lecturas antiguas, sino un principio gramatical que permite al lector moderno leer el texto de esta manera. Otra afirmación de Boer equilibra un poco su aseveración anterior y reconoce que la expresión

27 Davidson, Richar M. (1995). Biblical Evidence for the Universality of the Genesis Blood. Origins, 22, 58-73. Revisado y ampliado bajo el mismo títuto en Creation, Catastrophe, and Calvary. John T. Baldwin (Ed.). Hagerstown, MD: Review and Herald. pp. 79-92.

28 Ibíd., 46. 
es una forma de transmitir la idea al lector original de que Dios acepta como suya la ofrenda. Afirma Boer lo siguiente:

El término hhyn hyr pareciera ser un término técnico en las prácticas de los sacrificios. Expresa la idea de que la divinidad acepta el sacrificio como suyo. Cuando la expresión aparece después de esta otra frase, para $Y H W H$, ליהוה esto no significa que se esté dirigiendo a $Y H W H$, que sea $Y H W H$ quien recibe la ofrenda "a $Y H W H$ " o "para $Y H W H$ " es una información totalmente superflua. El significado es: el sacrificio es de $Y H W H$ Dios reconoce la ofrenda como suya ${ }^{29}$.

Los fundamentos literarios y gramaticales en que se apoya Boer son consistentes con la gramática hebrea. Ritchie (2000), en este sentido, afirma:

En pasajes tales como aquel en donde Noé ofrece un sacrificio a Dios después del diluvio, no es hasta que el aroma de un sacrificio hecho en forma correcta llegue al cielo que la deidad responde a la humanidad y contesta sus oraciones. Génesis 8,21 declara: Y cuando el Señor olió el aroma agradable, el Señor dijo en su corazón, nunca jamás maldeciré nuevamente la tierra (p. 59-73).

\section{REFLEXIÓN TEOLÓGICA}

El uso de las ofrendas quemadas con el propósito de generar aroma a la deidad era una práctica común en las religiones del Antiguo Cercano Oriente. La práctica se encontraba en diferentes comunidades religiosas en formatos distintos. No obstante, la pregunta que al respecto se formula es si el aroma que emanaba de dichos sacrificios se hacía siempre para satisfacer los sentidos de la deidad. Más aún, ¿será que estos rituales tenían el mismo concepto teológico en Israel que en los pueblos vecinos?

La teología del Antiguo Testamento, contrario a algunas posturas que han analizado la frase en el ritual hebreo, no presenta a un Dios que necesita ser calmado o manipulado para bendecir al adorador. Por el contrario, el

29 Ibíd. 
Antiguo Testamento presenta a $Y H W H$ como un Dios soberano, quien toma por su propia cuenta la iniciativa de favorecer al hombre. En la relación de pacto entre $Y H W H$ y su pueblo es la deidad quien da el primer paso, ya sea para salvar a su pueblo o para conducirlos por sendas de prosperidad. El Dios de los hebreos no esperaba las ofrendas para obrar a favor de su pueblo como los dioses del Antiguo Cercano Oriente, como lo describen los textos analizados sobre esta práctica en los pueblos vecinos de los hebreos.

Por el otro lado, el concepto de "expiación," o sea, la búsqueda de limpieza espiritual o santidad, es un motivo recurrente al acercarse el adorador hebreo a $Y H W H$ con estas ofrendas quemadas. Es el propósito más explícito expresado en el discurso hebreo en torno a los sacrificios quemados. Como se pudo apreciar en el cuadro anterior, el motivo predominante de estas ofrendas es expiatorio. Pero, exactamente cuál de estos conceptos teológicos refleja el uso de la palabra ניהה, no es claro para el lector a simple vista en la redacción. No obstante, teniendo en cuenta que la palabra no describe la satisfacción de los Sentidos, sino la satisfacción por una obra cumplida o deseo alcanzado, se puede entender que el uso de esta palabra en el contexto de las ofrendas a $Y H W H$ pretende transmitir la idea de aceptación o satisfacción de su parte.

En otras palabras, después que $Y H W H$ respiró el aroma de la ofrenda de Noé registrado en Gn. 8,21, no volvió a registrarse un acto en que la deidad sea el sujeto que respire o que percibe el aroma de los sacrificios en dichos rituales. Pero, en los libros del Pentateuco el ideal de todo oferente que presenta un holocausto se dirige a $Y H W H$ para que su ofrenda sea aceptada, considerada de ofrenda agradable y por lo tanto, constantemente se recuerda al adorador que su ofrenda debe ser de "aroma aceptable a $Y H W H$ ".

El aroma en los rituales hebreos refleja una teología peculiar; aunque comparte algunas similitudes con las mismas prácticas en las religiones del Antiguo Cercano Oriente, se distingue ampliamente en la teología de los mismos. Cuando $Y H W H$ percibe el aroma de los sacrificios es porque lo acepta como tal. En cambio el aroma de los sacrificios de las religiones circundantes tenía el propósito de persuadir a los dioses a actuar a favor de los fieles. En cambio, la deidad en la religión hebrea actuaba de manera soberana por iniciativa propia para favorecer a sus fieles. Como condición para aceptar las ofrendas fijaba instrucciones o procedimientos claros y detallados, una ofrenda fuera de esos parámetros era desechada o rechazada. 
Para entender mejor el pensamiento teológico sobre el tema del aroma en el culto a $Y H W H$, es indispensable ubicar el evento del diluvio y los actos de la deidad en el marco de los temas teológicos del libro en general, y en particular, en el contexto teológico de los 11 primeros capítulos del libro. Esta primera sección (Gn. 1-11) ha sido objeto de estudio desde la perspectiva histórica, literaria y teológica ${ }^{30}$. El consenso general es que esta sección carece de un fundamento histórico y por lo ende, no hay bases históricas válidas sobre las cuales establecer una teología compatible como en el resto del libro ${ }^{31}$. Por tal motivo, esta primera sección ha sido separada literaria y teológicamente del resto del libro. No obstante, en la última década han surgido algunas propuestas de interpretación sobre esta sección del Génesis que motivan a una lectura teológica sobre el evento del diluvio, sustentadas en aspectos literarios y estructurales de la perícopa.

La primera posición la describe Robert D. Branso, quien hace un llamado al cambio de paradigma en la interpretación de estos primeros 11 capítulos de Génesis (Branson, 2009, pp. 141-156). Afirma que el autor del Génesis, un teólogo israelita, utilizó el material cultural de los pueblos mesopotámicos como un vehículo para transmitir la teología hebrea sobre los orígenes. Descarta que haya fundamentos históricos para esta narración, pero reconoce que en estos capítulos hay una teología sobre la creación y los orígenes. El único Dios que crea, ordena, destruye y recrea la tierra como un acto de soberanía divina (Branson, 2009).

La segunda posición reconoce que el texto es de naturaleza teológica, y fundamenta la teología de esta sección en estructuras literarias y no en bases históricas (Hall, 2001, pp. 56-75). Coincide con la primera postura en el sentido de que reconoce en el relato al Dios que crea y recrea por su voluntad. Pero encuentra un paralelo entre el primer capítulo de Génesis y

30 Hall, Kevin (2009). The theology of Genesis 1-11. Southwestern Journal of Theology, 44 (1), 56-75. Branson, Robert D. (2009). Shifting Paradigms for Interpreting Genesis 1-11. Wesleyan Theological Journal, 44 (1), 141-156.

31 Gingerich, Owen. (1993) Space, Time, and Beyond: Place of God in the Cosmos. A paper presented for the 1992 Gross Memorial Lecture at Valparaiso University (Valparaiso, IN, 1993), 23. Fisher, Eugene (1970). Gilgamesh and Genesis: The Flood story in context. Catholic Biblical Quarterly, 32, 392-403. James B. Pritchard, ed., Ancient Near Eastern Text Relating to the Old Testament, 3 ed. Princeton: Princeton University Press. 
la narración sobre el diluvio (1,2-10, 20-25; 7,11-22; 8.1-13-17). Considera que la historia de la creación del mundo, la creación de la humanidad, el juicio de $Y H W H$ sobre la humanidad expresado en el diluvio, el rescate y la recreación, son una sola historia. Por último, hay quienes reconocen en los primeros 11 capítulos de Génesis una unidad literaria y teológica sobre fundamentos históricos. Richard Davidson declara que la estructura literaria de todo el libro de Génesis gira alrededor de la palabra toledoth, amarrando así la narración del diluvio con el resto del libro y, por ende, revela una unidad histórica en todo el libro, incluyendo los capítulos 6-9. En otras palabras, los 11 primeros capítulos están incluidos en el registro histórico de los orígenes del mundo en la misma estructura literaria y teológica que el resto del libro de Génesis; por consiguiente, no descarta que la teología de los capítulos 6-9, tiene los mismos fundamentos históricos que el resto del libro.

En conclusión, se puede afirmar que la catástrofe universal como lo registra Génesis constituye un acto soberano de $Y H W H$, en el mismo sentido de sus actos creativos en los primeros tres capítulos del libro. Así como creó y ordenó los elementos creados, así también reversó lo creado cuando apareció el pecado, afectando así la naturaleza y al hombre mismo. Es también un acto de soberanía de la deidad cuando decide destruir todo lo creado por medio de un diluvio debido a la intensificación del pecado y con el mismo espíritu lo recreó después de la catástrofe. No hay indicio alguno de que el aroma y su efecto emocional fuesen el factor que lo impulsó a actuar cuando Noé ofreció su holocausto. En un acto de satisfacción de parte de $Y H W H$, percibió el aroma del sacrificio y lo aceptó como un acto acorde a su santa voluntad.

\section{LISTA DE REFERENCIAS}

Anderson, Gary. (1987). Sacrifices and Offerings in Ancient Israel: Studies in their Social and Political Importance. Atlanta: Scholars Press.

Branson, Robert D. (2009). Shifting Paradigms for Interpreting Genesis 1-11. Wesleyan Theological Journal. 44, 1.

Brown, Francis. (1979). The New Brown-Driver-Briggs-Gesenius Hebrew and English Lexicon. Peabody, Massachusetts: Hendrickson Publishers. 
Caird, Gorge B. (1980). The Language and Imagery of the Bible. London: Duckworth.

Craig C. Broyles. (2201). Interpreting the Old Testament: A Guide for Exegesis. Grand Rapids: Baker Academic.

Cassuto, Umberto. (1997). A Commentary on the Book of Genesis. Jerusalem: The Magnes Press, The Hebrew University.

Fisher, Eugene. (1970). Gilgamesh and Genesis: The Flood story in context. Catholic Biblical Quarterly, 32.

Gane, Roy. (2008). Ritual and Rhetoric in Leviticus: from sacrifice to scripture. Catholic Biblical Quarterly (CBQ) 70, no. 31.

Gispert, Carlos. (1987). Diccionario Ilustrado Océano de la Lengua Española. Barcelona: Ediciones Océano, S.A.

Hess, Richard S. (1978). One Hundred Years of Comparison Studies on Genesis 1-11: Ancient Near Easter, Literary and Near Eastern Approach to Genesis 1-11. Richard S. Hess y David Toshio Tsumura (Eds.). Glasgow Bible College.

Hall, Kevin. (2001). The theology of Genesis 1-11. Southwestern Journal of Theology, 44,1 .

Gingerich, Owen. (1993). Space, Time, and Beyond: Place of God in the Cosmos. A paper presented for the 1992 Gross Memorial Lecture at Valparaiso University. Valparaiso, IN.

Jenson, Philip. (2006). Sacrifice and symbol: Biblical Selamim in a ritual perspective. Journal for the Study of the Old Testament (JSOT) 30, 5.

Jon D. Levenson. (1987). Justice and Righteousness in Israel and the Nations: Equality and Freedom in Ancient Israel in Light of Social Justice in Ancient Near East. Journal of Biblical Language, 106, 3.

Joan Scurlock. (1998). The Techniques of Sacrifice of Animal in Israel and Ancient Mesopotamia: New Insight Through Comparison, Part 2. Andrews University Study. Vol 44. 2.

Kathryn Mcklymond. (2004). The nature and elements in sacrificial ritual, Method and Theory in the Study of Religion 6, 4.

Klawans, Jonathan. (1977). Purity, Sacrifice, and the Temple: Symbolism and Supersessionism in the Study of Ancient Judaism. Journal for the Study of Ancient Judaism 1.

King, M. A. (1984). The Burnt Offering: A Sweet Aroma to God. Moody Monthly, 1984. 
Leach, Edmund R. (1968). "Ritual". International Encyclopedia of the Social Sciences, 13 vols. David L. Sills (Ed.). New York: The Free Press.

Mathews, K. A. (1996). Geneisis 1-11: An Exegetical and Theological Exposition of Scripture. Nashville: Broadman and Holman Publishing.

Muller, Reihhard. (2008). Jahweals Wettergott: Studienzur Althebruischen Kutlyrick anhand ausgewahhtler Psalmaen. Berlin: de Gruyter.

Nakhai, Beth Albert. (201). Archaeology and the Religions of Canaan and Israel. en Arqueology and the Religions of Canaan and Israel, Asor Books 7 vol., ed., Victor Mattews. Boston MA: American School of Oriental Research.

Oswalt, John N. (2009). The Bible Among the Myths: Unique Revelation or just Ancient Literature? Gran Rapids: Zondervan.

Romerowski, Sylvain. (2007). Old Testament Sacrifices and Reconciliation. European Journal of Theology, 16, 1.

Stuart, Douglas. (2000). Old Testament Exegesis: A Handbook for Students and Pastors. Kentucky: John Knox Press.

Turner, Laurence A. Genesis (Sheffield, England: Sheffield Academic Press, 2000), 50-51; H.C. Leupold, Exposition of Genesis, 1 vol. Grand Rapids, Mcihigan: Baker Book House, 1990.

Waltke, Bruce K. (2007). An Old Testament Theology: An Exegetical, Canonical, and Thematic approach. Grand Rapids: Zondervan.

Wenham, Gordon J. (2008). "Genesis”, en Theological Interpretation of the Old Testament: A book by book survey, ed. Kevin J. Vanhoozer. Grand Rapids: Baker Academic.

William W. Hallo, William W. y K. Lawson eds.. (2003). The Context of Scripture, vol 1. Leiden, Netherlands: Brill.

Wulf, David. (1992). Current Studies on Rituals: Perspectives for the Psychology of Religion. Journal for the Scientific Study of Religion 31, 2. 